\title{
Fly Ash on the Waste Cathode Ray Tube Glass Mortar Alkali Aggregate Reaction Inhibition Studies
}

\author{
Xue Song ${ }^{1, a}$, Jianjun Shi, ${ }^{1, b}$,Zhaoyu Chen ${ }^{1, c}$ \\ ${ }^{1}$ School of Urban Construction, University of South China, Hengyang, Hunan Province,China \\ a228964818@qq.com, bjj6621@163.com, ${ }^{\text {c2 } 270245591 @ q q . c o m ~}$
}

\begin{abstract}
Keywords: Waste cathode ray tube glass; Alkali-aggregate reaction;Accelerated Mortar Bar Test; Fly ash

Abstract. With finely ground waste cathode ray tube glass sand, respectively replace $20 \%, 40 \%$, $60 \%$ the proportion of ordinary sand in mortar, fly ash as mineral admixture in $0 \%, 10 \%, 20 \%, 30 \%$ the proportion of replacing cement.A total of 12 sets of mortar specimens were prepared.Use Accelerated Mortar Bar Test (ASTM1260) to measure mortar specimens alkali aggregate reaction expansion at 3D, 7D, 14D, 28D. The results show that: CRT glass is an alkali active substance, expansion will become larger with the increase of CRT glass content in the mortar specimen. Fly ash can restrain CRT glass mortar ASR expansion, all adding fly ash specimens 14D expansion rate is less than $0.1 \%$, the swelling degree of restraint increases with the fly ash, ash up to $20 \%$ when we have been able to significantly restrain the expansion.
\end{abstract}

\section{Introduction}

Waste cathode ray tube (CRT) glass is a kind of harmful electronic waste, use ground CRT glass sand as radiation concrete aggregate has become one way to handle this waste ${ }^{[1-2]}$. Glass concrete aggregate alkali-silica reaction (ASR) has been a problem in concrete durability aspects, since CRT also belong to the crystal structure of silica-rich glass products, which lead to its very active in an alkaline environment. To use waste CRT glass in the preparation of concrete, the biggest problem is how to control the expansion of concrete.

GuoShuai Xie $^{[3]}$ mentioned the incorporation of blast furnace slag powder, fly ash, silica fume and other auxiliary materials in concrete can reduce or even eliminate alkali-aggregate reaction, effectively reducing the risk of glass concrete expands hazards;Tung-Chai Ling,Chi-Sun Poon ${ }^{[4]}$ compared the ordinary glass, CRT glass replace ordinary sand in mortar ASR reaction,it showed that CRT glass mortar expansion are larger than ordinary glass mortar,indicating that CRT glass aggregate more prone to swell in the same environment than ordinary glass;Hui Zhao ${ }^{[5]}$, with $25 \%$ of fly ash and ground slag as CRT mortar mineral admixtures, fly ash compared to ground slag has better inhibition effect was found on the CRT ASR mortar.Current research shows that fly ash as mineral admixture can be used to inhibit CRT glass concrete alkali aggregate reaction,but which content for fly ash in different CRT mortar turn out better alkali-aggregate reaction inhibiting effect , also needs further experiments.

In this study, three kinds of CRT glass mortar each added four kinds of different content fly ash, use Accelerated Mortar Bar Test (ASTM C1260) for all specimens carried alkali aggregate reaction expansion measurement in3D, 7D, 14D, 28D.By comparison and analysis, the effect of different content fly ash on the reaction of alkali aggregate reaction of CRT mortar could be obtained.

\section{Test raw materials, specimen production and measurement}

\section{Test raw materials}

Test cement is P.C 42.5 ordinary portland cement, fly ash is secondary ash from a power plant, fine aggregates are respectively river sand and CRT glass.The sand is form local Xiangjiang river, after drying, screened to meet the grading requirements.CRT glass is recovered from a recycling plant, after mechanical disruption, all ground to a particle size less than $5 \mathrm{~mm}$ or less. Conservation alkaline solution of sodium hydroxide was formulated at a concentration of $1 \mathrm{~mol} / \mathrm{L}$. 


\section{Specimen production and mix proportions}

Experiment with reference to ASTM C1260 requirements, take cement and sample mass ratio of 1: 2.25, water-cement ratio of 0.47,aggregate level using five kinds of grain, including $2.5 \sim 5 \mathrm{~mm}$ diameter accounted for $10 \%, 0.315 \sim 0.63 \mathrm{~mm}, 0.63 \sim 1.25 \mathrm{~mm}, 1.25 \sim 2.5 \mathrm{~mm}$ diameter each 25\%, $0.16 \sim 0.315 \mathrm{~mm}$ diameter accounted for $15 \%$ of the total aggregate, CRT respectively replace $20 \%$, $40 \%, 60 \%$ the proportion of ordinary sand in mortar aggregates. The 3 groups were represented by $\mathrm{AF}, \mathrm{BF}$ and $\mathrm{CF}$, each group is divided into four small groups depending on the fly ash content, fly ash as mineral admixture in $0 \%, 10 \%, 20 \%, 30 \%$ the proportion of replacing cement. Groups AF-0, BF- 0 , CF-0 are three control groups which not mixed with fly ash. Finally made the 12 groups of $25 \mathrm{~mm} x$ $25 \mathrm{~mm} \times 285 \mathrm{~mm}$ mortar bars. Table 1 shows the specific mix proportions.

Table 1

Mix proportions of mortar bars

\begin{tabular}{cccccc} 
Sample No. & Cement[g] & Fly ash[g] & River sand[g] & CRT[g] & Water[g] \\
\hline AF-0 & 440 & 0 & 792 & 198 & 207 \\
AF-10 & 396 & 44 & 792 & 198 & 207 \\
AF-20 & 352 & 88 & 792 & 198 & 207 \\
AF-30 & 308 & 132 & 792 & 198 & 207 \\
BF-0 & 440 & 0 & 594 & 396 & 207 \\
BF-10 & 396 & 44 & 594 & 396 & 207 \\
BF-20 & 352 & 88 & 594 & 396 & 207 \\
BF-30 & 308 & 132 & 594 & 396 & 207 \\
CF-0 & 440 & 0 & 396 & 594 & 207 \\
CF-10 & 396 & 44 & 396 & 594 & 207 \\
CF-20 & 352 & 88 & 396 & 594 & 207 \\
CF-30 & 308 & 132 & 396 & 594 & 207 \\
\hline
\end{tabular}

\section{Specimen conservation and measurement}

After the specimen is made, put them into $80^{\circ} \mathrm{C} \pm 2{ }^{\circ} \mathrm{C}$ water bath curing oven tank.Preventive maintenance $24 \mathrm{~h}$, measured the initial length, then put the test pieces into $80^{\circ} \mathrm{C} \pm 2^{\circ} \mathrm{C}$ sufficient $\mathrm{NaOH}$ liquid conservation container,respectively, in 3D, 7D, 14D, 28D measured specimen length. The elongation of the specimen was measured like Figure 1.Calculated each time length expansion rate and 28D expansion inhibition rate. The length expansion rate is according to Eq. 1:

$$
\mathrm{P}=\left(\mathrm{L}_{\mathrm{t}}-\mathrm{L}_{0}\right) /\left(\mathrm{L}_{0}-2 \mathrm{D}\right) \times 100 \%
$$

In Eq.1: $\mathrm{L}_{\mathrm{t}}$ refers to the different age of specimens measuring length, $\mathrm{L}_{0}$ refers to the beginning of the specimen length, $\mathrm{D}$ refers to the length of the test piece at both ends of the probe.

The 28D expansion inhibition rate according to Eq. 2:

$$
\mathrm{Q}=\left(\mathrm{Pn}-\mathrm{P}_{0}\right) / \mathrm{P}_{0}
$$

In Eq.2:Pn refers to the expansion rate of the specimens in the $28 \mathrm{D}, \mathrm{P}_{0}$ refers to the corresponding control group specimens 28D expansion.

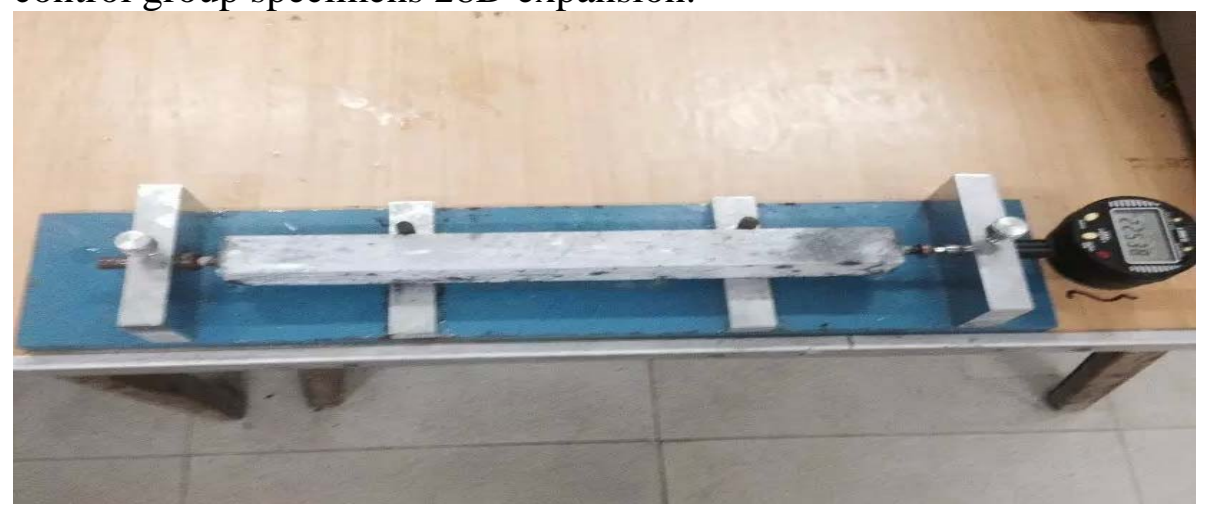

Fig.1 The measurement of the specimen elongation 


\section{Test results and discussion}

The calculated test data have been showed in Table 2.The three control group AF-0, BF-0, CF-0 14D specimens expansion rate are all more than $0.1 \%$, CF- 0 group $28 \mathrm{D}$ expansion rate exceeds $0.2 \%$, based on CRT is an alkali-reactive aggregates,So when the fly ash is the same, with the increase in CRT content, the expansion of the specimen correspondingly larger. To observe Figures 2,3, 4, when the CRT content is the same, by comparing different volume fly ash groups 28D expansion inhibition rate, it found that the more fly ash in mortar bar,the inhibition of alkali aggregate reaction expansion were better, all adding fly ash specimens $14 \mathrm{D}$ expansion rate is less than 0.1 percent. When adding a small amount of fly ash (10\%), it can produce obvious inhibitory effect.But this time with a certain degree of expansion curve also continued to rise, indicating that the inhibition was not complete; when the fly ash content of more than $20 \%$, the specimen has been very slow expansion curve rises; when the fly ash content reached $30 \%$, all 28D expansion inhibition rate almost reached $90 \%$. It clearly shows that fly ash as admixture, when the content control between $20 \%-30 \%$ of the cement,their inhibition to CRT mortar ASR expansion is efficient and obvious.

Its inhibition mechanism could be explained in the following aspects: Alkali content of fly ash is generally lower than that of cement, which is used as admixtures, reducing the alkali content of mortar, played a dilution effect;fly ash generated low $\mathrm{Ca} / \mathrm{Si}$ ratio of calcium silicate hydrate by the volcano ash reaction of calcium hydroxide, therefore,its adsorption of alkali, can also reduce the $\mathrm{pH}$ of solution; different fineness of fly ash and cement, they can each filling, increase the density of the system, the contact between the alkali metal cation and the active aggregate becomes difficult, can reduce the possibility of alkali aggregate reaction.

\section{Table 2}

\section{Experimental data and results}

\begin{tabular}{|c|c|c|c|c|c|}
\hline \multirow{2}{*}{ Sample No. } & \multicolumn{4}{|c|}{ Expansion ratio[\%] } & \multirow{2}{*}{$\begin{array}{l}\text { 28D expansion } \\
\text { inhibition } \\
\text { rate[\%] }\end{array}$} \\
\hline & $3 \mathrm{D}$ & 7D & $14 \mathrm{D}$ & $28 \mathrm{D}$ & \\
\hline AF-0 & 0.011 & 0.053 & 0.131 & 0.184 & \\
\hline AF-10 & 0.008 & 0.017 & 0.032 & 0.051 & 72.3 \\
\hline AF-20 & 0.006 & 0.007 & 0.015 & 0.024 & 86.9 \\
\hline AF-30 & 0.001 & 0.002 & 0.008 & 0.019 & 89.7 \\
\hline BF-0 & 0.056 & 0.076 & 0.137 & 0.198 & \\
\hline BF-10 & 0.014 & 0.025 & 0.043 & 0.067 & 66.2 \\
\hline BF-20 & 0.004 & 0.007 & 0.018 & 0.031 & 84.3 \\
\hline BF-30 & 0.001 & 0.005 & 0.014 & 0.021 & 89.4 \\
\hline CF-0 & 0.017 & 0.058 & 0.162 & 0.247 & \\
\hline CF-10 & 0.018 & 0.034 & 0.053 & 0.075 & 69.6 \\
\hline CF-20 & 0.008 & 0.011 & 0.023 & 0.035 & 85.8 \\
\hline CF-30 & 0.014 & 0.020 & 0.022 & 0.023 & 90.7 \\
\hline
\end{tabular}

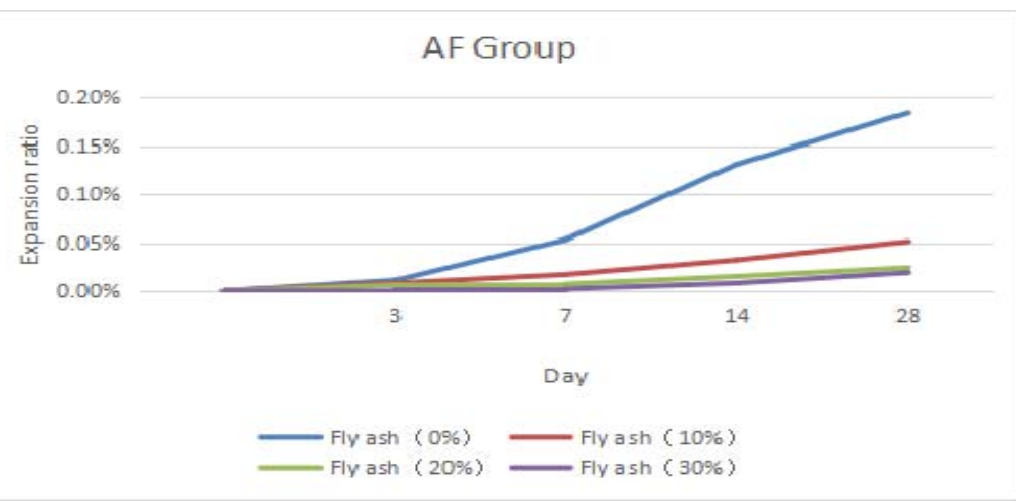

Fig.2 AF group specimens expansion ratio curve 


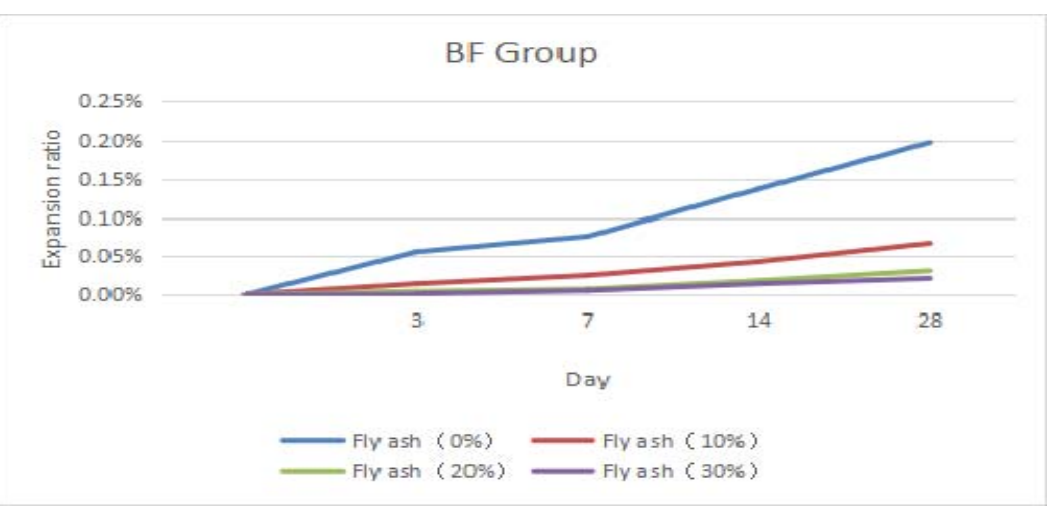

Fig.3 BF group specimens expansion ratio curve

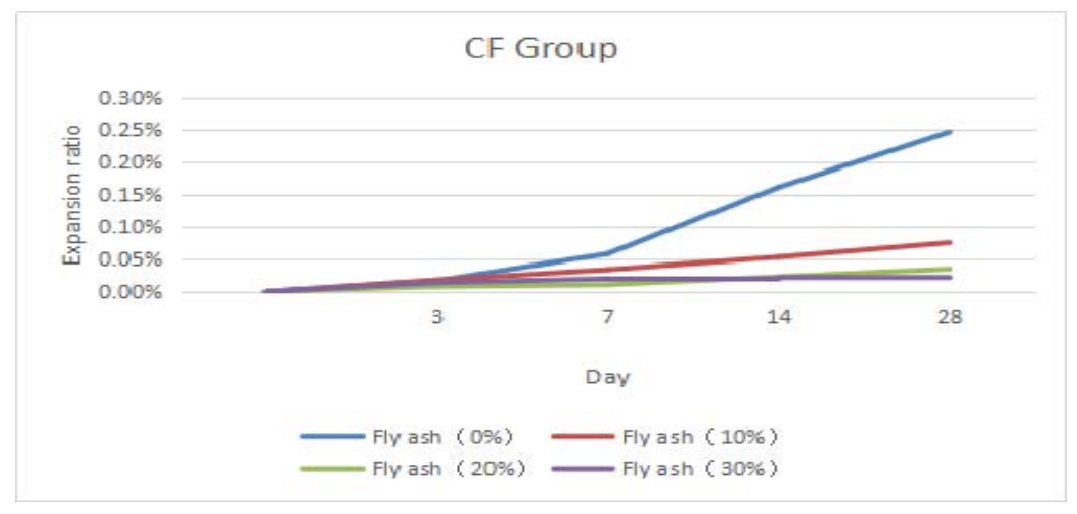

Fig.4 CF group specimens expansion ratio curve

\section{Conclusions}

The CRT is an alkali-reactive aggregates, the higher the proportion of the aggregate, the more intense ASR expansion. Fly ash as mineral admixtures, can play a good inhibition to alkali-aggregate reaction in CRT mortar, the inhibitory effect and fly ash has a certain relationship, the greater the amount of fly ash, the better inhibition effect. When the fly ash content is more than $20 \%$, can achieve the ideal effect of inhibition. But from the practical engineering point of view, too much fly ash will affect the strength and working performance of concrete.It is recommended that the amount of ash fly mixed in concrete should between $20 \%$ to $30 \%$.

Based on CRT this alkali active aggregate, in addition to use fly ash do inhibitor for alkali aggregate reaction, but also consider other mineral such as silica fume admixtures or lithium salt and other chemical admixtures, to seek more economical and better inhibitory effect inhibitors.

\section{Acknowledgements}

This work was financially supported by Hunan Provincial Natural Science Foundation, CRT cullet radiation experiments and mechanism of concrete research(14JJ2083).

\section{References}

[1] Yingliang Tian,Yanli, Shao,Shibing Sun .CRT glass recycling method and recycling pathway [J] Materials reported: Review articles, 2013,27 (8): 74-77; In Chinese.

[2] Chi-sun Poon,Hui Zhao,Shicong Kou.The presence of research status and development trend of radiation concrete problem [J] Wuhan University of Technology, 2011,33 (1): 45-51; In Chinese. 
[3] Guoshuai Xie,Yaning Kong,Shuhua Liu.Glass concrete alkali aggregate reaction Progress [J] New materials industry, 2012, (7): 65-71,In Chinese.

[4] Tung-Chai, Chi-Sun Poon.A comparative study on the feasible use of recycled beverage and CRT funnel glass as fine aggregate in cement mortar[J]. Journal of Cleaner Production, 2012, (29-30): :46-52.

[5] Hui Zhao,Wei Sun. [J] Journal of the Chinese Ceramic Society, 2012, 40 (2): 240-246,In Chinese. 